\title{
The Design of Micro Permanent Magnetic Synchronous Machine Control System Based on DSP
}

\author{
Jin Chen ${ }^{1, *}$, Xiaogang $\mathrm{Xie}^{2}$ and Mengjia Dai ${ }^{2}$ \\ ${ }^{1}$ Shanghai Second Polytechnic University, China \\ ${ }^{2}$ Shanghai Maritime University, China \\ ${ }^{*}$ Corresponding author
}

\begin{abstract}
This paper built the simulation model of vector control system of permanent magnetic synchronous machine based on MATLAB SIMULINK. The simulation results verified the feasibility of the vector control system on PMSM. The hardware circuit of motor control and driver board which used digital signal processor TMS320F28335 as a control chip has been made and the software of PMSM control system has been designed. The results of experiment verified the correctness and rationality of the system hardware and software.
\end{abstract}

\section{Keywords-component; DSP ;PMSM ; Vector Control}

\section{INTRODUCTION}

In recent years, with the deepening of servo research, permanent magnetic synchronous machine, due to its select function, has been used widely in computer numerical control machine tools, processing production, aerospace and other industries. There are many AC servo drivers which are little vibration, low noise, high precision and high speed in print machine, small and medium-sized engraving machine, electronic equipment, computer numerical control machine tools and other automatic device [1]. However, if it is used in micro-electronic mechanical control system, the cost will quite high[2]. Therefore, this paper developed a low-cost micro permanent magnetic machine control system which applied in industry and civil industry.

\section{AnAlysis of CONTROl StRAtegy OF PERMANENT MAGNETIC SYNCHRONOUS MACHINE}

The basic idea of vector control is that using three-phase AC motor to simulate the torque control of DC motor, on the orientation coordinate of magnetic field, decomposing the current vector into field current and torque current components which are vertical and independence to each other and can be adjusted respectively. In this paper, the decoupling control of the direct axis (and) of the stator current is completed, which makes the PMSM have superior operating characteristics [6].

The block diagram of permanent magnetic synchronous machine vector control is shown in Figure I. The system mainly consists of permanent magnetic synchronous machine module, speed/current loop module, coordinate transformation module, SVPWM module, inverter module and measurement module. The control process is that comparing the speed command $\omega_{\text {ref }}$ and the detected signal of rotor speed $\omega_{\mathrm{e}}$ and developing output signals $i_{\text {qref }}$ through adjustment of the speed control loop and resulting input of current control loop by subtracting feedback variable $\left(i_{q}\right), i_{\text {dref }}$ is 0 . Converting $\mathrm{i}_{\mathrm{d}}$ and $\mathrm{i}_{\mathrm{q}}$ into stator three-phase current through coordinate transformation. Then, inverter circuit can be driven by six way PWM wave which is generated by PWM module and generates three-phase sine voltage which has variable frequency and amplitude to drive the motor.

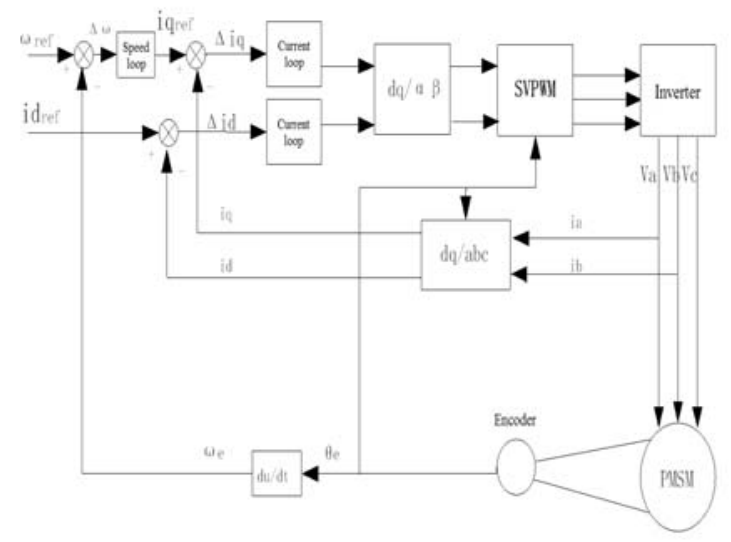

FIGURE I. THE STRUCTURE DIAGRAM OF PMSM VECTOR CONTROL

Under the dq rotating coordinate system [4], electromagnetic torque is

$$
T_{e}=n_{p}\left(\psi_{f} i_{q}+\left(L_{d}-L_{q}\right) i_{d} i_{q}\right) \frac{1}{2}
$$

order $\mathrm{i}_{\mathrm{d}}=0$, then electromagnetic torque is

$$
T_{\mathrm{e}}=n_{p} \psi_{f} \times i_{q}
$$

so torque is controlled by $\mathrm{i}_{\mathrm{q}}$.

\section{MODEL AND SIMULATION RESULTS OF PMSM VECTOR CONTROL}

The simulation model of PMSM vector control system is 
shown in Figure II. In simulation, stator resistance of the motor is $R=8.2 \Omega$, equivalent inductance is $L=0.000835 \mathrm{H}$, the number of poles is $\mathrm{p}=3$, rotor flux is $\psi_{\mathrm{f}}=0.175 \mathrm{~Wb} \quad$, moment of inertia is $J=1.87 \mathrm{e}-4 \mathrm{~kg} \bullet \mathrm{m}^{2}$.

Set the proportion and integral coefficient of the current control loop are 10 and 8 respectively, and the proportion and integral coefficient of the speed control loop are 0.5 and 0.8 .

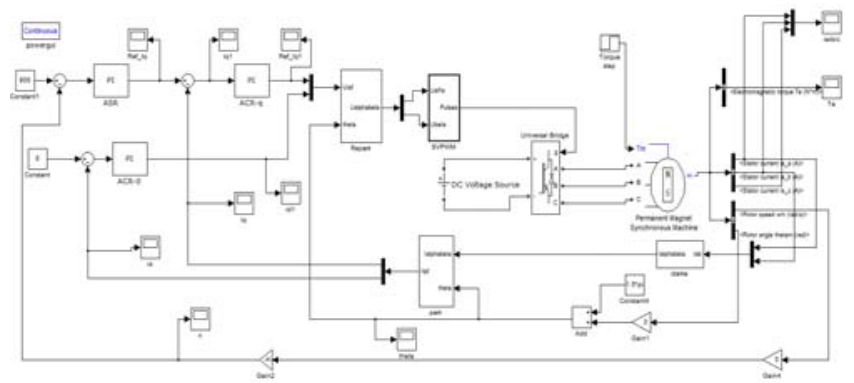

FIGURE II. PMSM VECTOR CONTROL SYSTEM MODEL WITH DOUBLE CLOSED-LOOP CONTROL

\section{A. No-load Start and in Steady State Operation}

The speed of motor is accelerated from 0 to $800 \mathrm{rpm}$, the motor run at 800rpm in steady state operation. At this time, the motor speed is shown in Figure III, the three phase current of stator is shown in Figure IV and the torque of motor is shown in Figure V.

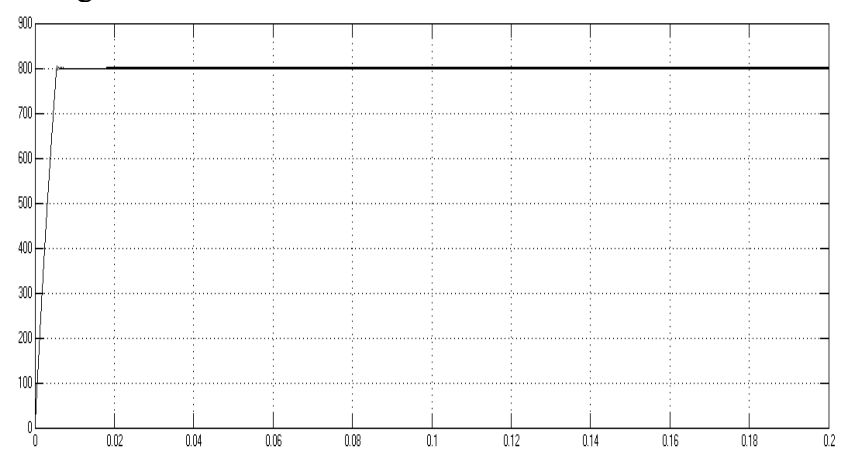

FIGURE III. THE SPEED OF MOTOR(RPM)

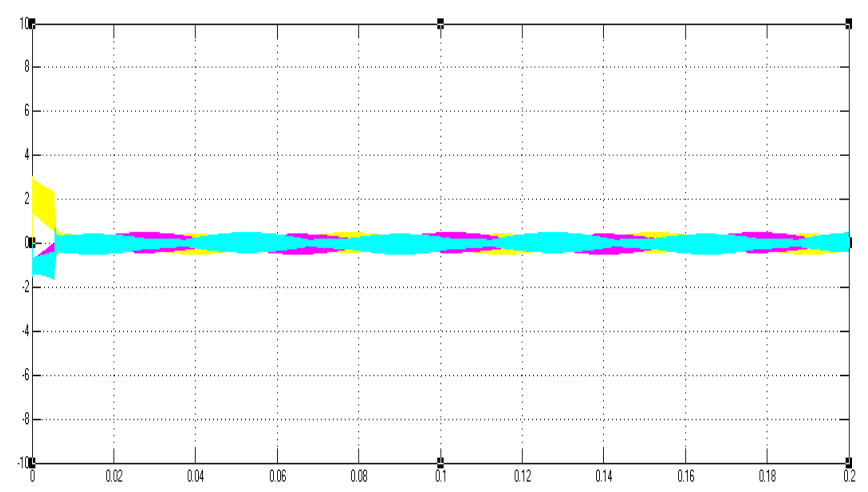

FIGURE IV. THREE PHASE CURRENT OF STATOR

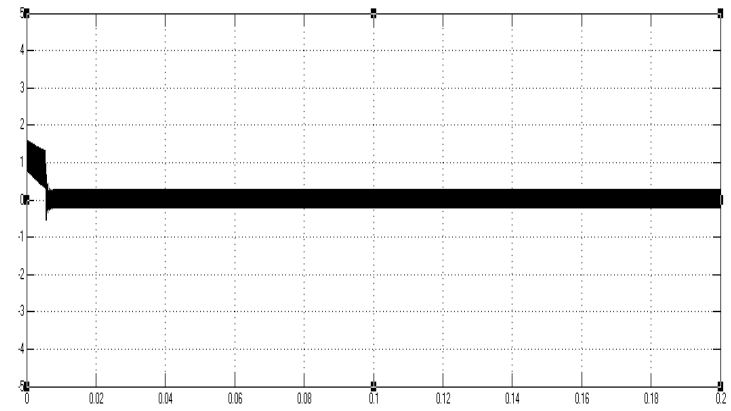

FIGURE V. THE CURVE OF MOTOR TORQUE

\section{B. Add Load Suddenly in Steady State Operation}

Adding load to motor at the moment of $0.05 \mathrm{~s}$, $T=0.8 N * M$, steady speed is $800 \mathrm{rpm}$. At this time, the speed of motor is shown in Figure VI, the three phase current of stator is shown in Figure VII and the torque of motor is shown in Figure VIII.

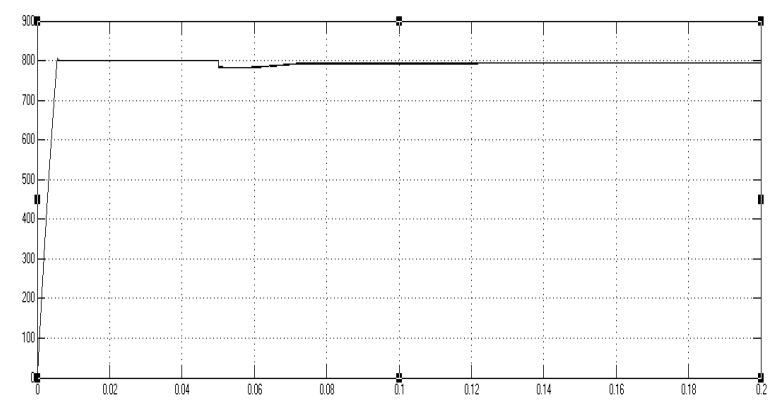

FIGURE VI. THE SPEED OF MOTOR(RPM)

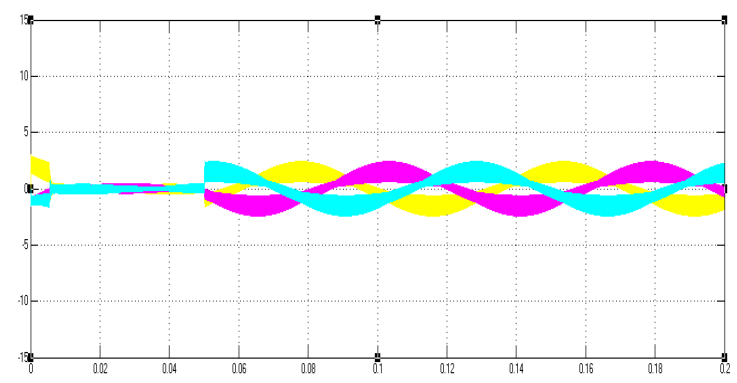

FIGURE VII. THREE PHASE CURRENT OF STATOR

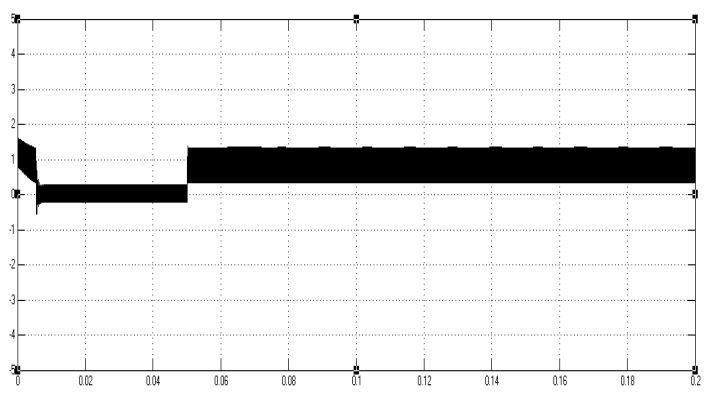

FIGURE VIII. HE CURVE OF MOTOR TORQUE 
The simulation results show that sine characteristics of stator phase current was not obvious when no-load start time was short and the speed increased fast. The reason of this phenomenon is that main load torque is viscous damping in the steady state and viscous damping is very small. Because adding current control PI regulator and speed control PI regulator as a double loop, the dynamic response of motor is very fast.

The rotor movement formula of motor is as follows.

$$
T_{\mathrm{e}}-T_{L}=J \frac{d \omega_{r}}{d t}
$$

$T_{\mathrm{e}}$ is electromagnetic torque, $T_{L}$ is load torque, $\mathrm{J}$ is moment of inertia, $\omega_{\mathrm{r}}$ is mechanical angular velocity of rotor. $\omega_{\mathrm{r}}$ is 0 when started, so MEMF is 0 . At this time, the current is quite high, so electromagnetic torque is quite high. When the motor was in a steady state, $\frac{\mathrm{d} \omega_{\mathrm{r}}}{\mathrm{dt}}=0, T_{\mathrm{e}}=T_{L}$. Eq. 1 shows that when $T_{L}$ increased, rotational speed dropped. As shown in Figure VI, at the location of 0.05 , rotational speed returns to stability soon because of the function of PI regulator. At this time, resistance current increase, as shown in Figure VII, and reach a steady state, which shows PI regulator has a strong anti-interference ability.

\section{THE DESIGN OF EXPERIMENT TESTING SYSTEM}

The experiment platform of PMSM control system shown in the paper mainly includes DC power supply module, the control board, power board, voltage/over-voltage sensor module, the encoder and PMSM, etc. The computer equipped with CCS6.0 integrated development environment, connected to the control board through the simulator XDS-100USB and completed debugging code and downloading program on CCS. The control board output PWM wave to drive power board and the motor is small power and surface post type sine PMSM, its rated voltage is $24 \mathrm{~V}$ and rated speed is $6000 \mathrm{r} / \mathrm{min}$.

The hardware structure of permanent magnetic synchronous motor servo control system is shown in Figure IX.

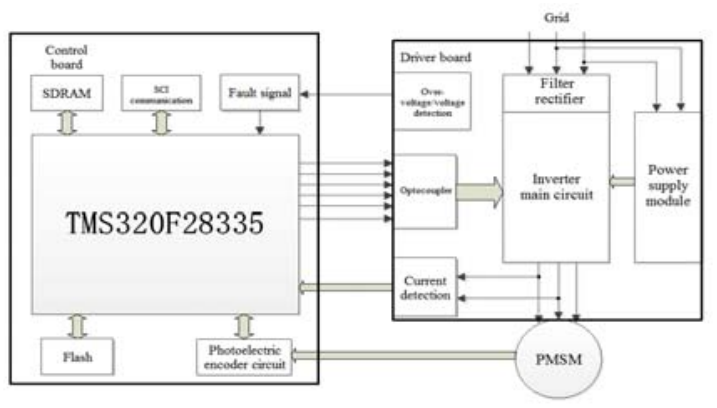

FIGURE IX. THE HARDWARE STRUCTURE OF SYSTEM
The working principle of the whole system is as follows. Rectifier circuit convert $220 \mathrm{~V}$ alternating current into DC bus voltage which motor control needs. Current detection circuit collects two phase current of PMSM, obtains permitted range of DSP after process and inputs to AD. Also, voltage/overvoltage detection circuit collects and obtains DC bus voltage which can be converted into digital signals for algorithm calculation by DSP AD sampling. Incremental photoelectric encoder transfers pulse common-mode signal into the QEP module of DSP through the encoder signal conditioning circuit. After dealt by DSP28335, the above collected signals are used in algorithm to output six way PWM drive signals which drive inverter circuit on the power board. The power drive board output three phase $\mathrm{AC}$ for permanent magnetic synchronous motor. At the situation of over current or over voltage, voltage/over-voltage detection circuit generates trigger level which generates the corresponding interrupt program to cut off PWM drive signal for system protection.

The PMSM used in the experiment is three phase and four level, technical parameters are shown in Table I.

TABLE I. MAIN PARAMETERS OF PMSM

\begin{tabular}{|c|c|c|}
\hline Parameters & Units & Figures \\
\hline Rated speed & {$[\mathrm{r} / \mathrm{min}]$} & 2500 \\
\hline Rated power & {$[\mathrm{kW}]$} & 1.5 \\
\hline Pole & {$[\mathrm{Pair}]$} & 4 \\
\hline Photoelectric encoder & {$[\mathrm{p} / \mathrm{r}]$} & 2500 \\
\hline Stator winding & {$[\Omega]$} & 4.2 \\
\hline Stator inductance & {$[\mathrm{mH}]$} & 26 \\
\hline
\end{tabular}

The system's frequency of PWM wave is $10 \mathrm{kHz}, \mathrm{SVPWM}$ waveform is shown in Figure X. As shown in the picture, there are two SVPWM waves of DSP28335 output by two compare units and its phase difference is $120^{\circ}$. The SVPWM waves are respectively used as drive signals of $\mathrm{A}$ and $\mathrm{B}$ phase of main circuit of power drive board. The waveform is Ma An wave after low-pass filter.

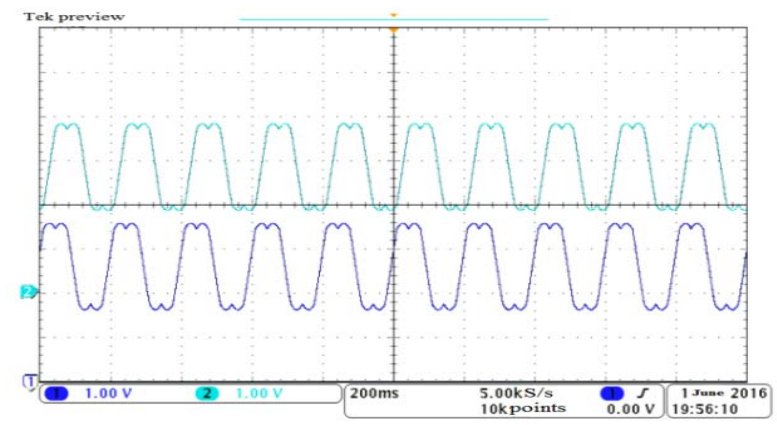

FIGURE X. DRIVE SIGNALS OF A AND B PHASE

In order to avoid simultaneous conduction on MOSFET of the same bridge arm of the inverter circuit, SVPWM design a dead time of $5 \mu \mathrm{s}$. As shown in Figure XI, on the left side of the picture shows waveform which is two way PWM control pulse of the same bridge arm and on the right side of the 
picture shows waveform which is driving signal of $\mathrm{A}$ and $\mathrm{B}$ phase.

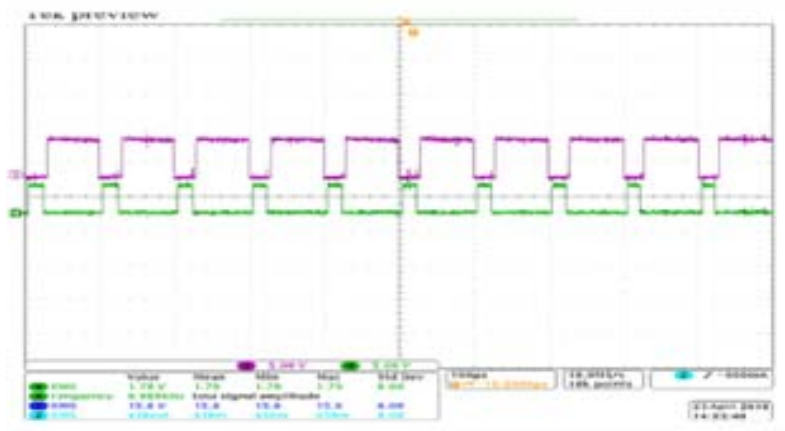

FIGURE XI. SVPWM WAVEFORM OF CONTROL SYSTEM

As shown in Figure XII is voltage and current waveform of A phase of PMSM on no-load. Voltage waveform approximate sine wave and its amplitude is about $40 \mathrm{~V}$. Current is close to zero. Figure $\mathrm{X}$ shows driving voltage signal of $\mathrm{A}$ phase and Figure XI shows phase voltage of A phase is near to sine wave, which is consistent with the analysis and simulation results of the vector control principle. So it is Illustrated that the correctness of the design of the hardware circuit and the SVPWM control algorithm.

\section{DISCUSSION OF THE EXPERIMENTAL RESULTS}

The paper discussed the control strategy of PMSM, in other words, it is a control strategy which is combined with the vector control and double closed-loop composed by classic speed and current. In MATLAB/SIMULINK, analyzing the parameters of PI controller and building the PMSM vector control simulation model. The simulation results show that this PMSM control system has good dynamic performance and verify the control strategy in this paper is feasible and effective. Many models are ideal in the simulation. Trimming the PI parameter near design value of theoretical derivation can get good effect.

The experimental platform designed by PMSM control system in this paper verified that the correctness of hardware circuit and software function through the experimental testing results.

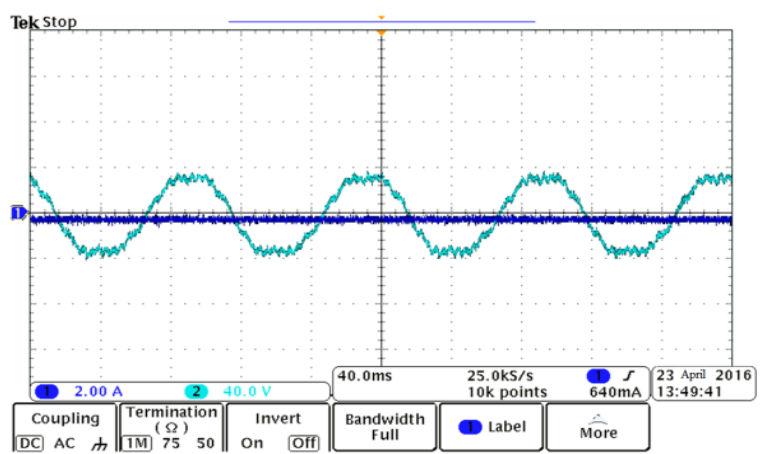

FIGURE XII. PHASE VOLTAGE AND STATOR CURRENT OF A PHASE OF PMSM ON NO-LOAD

\section{ACKNOWLEDGEMENT}

The research work was supported by Shanghai Second Polytechnic University key subject construction project (Project No. XXKPY1609).

The research work was supported by the Graduate Foundation of Shanghai Second Polytechnic University.

\section{REFERENCES}

[1] D K Yuan, Y D Xu, X T Li. Variable frequency speed control of permanent magnet synchronous motor and its control [M]. Beijing: China Machine Press, 2015.

[2] J Chen, J F Xu, Z B Yang. Direct torque control for servo motor [J]. Control engineering. 2003, 10(2):179-181.

[3] Liguo Q, Haibo H, Yourui H. Fractional order PID controller based on particle swarm optimization implemented with FPGA[C]. IEEE Computer Society: 165-169.

[4] N G Hong. Simulation of power electronic and electric machine control system technology [M]. Beijing: China Machine Press, 2013.

[5] Q Chen, G Z Wu. Adaptive Neural Control of Permanent Magnet Synchronous Motor with Variable Load[J].The Journal of New Industrialization. 2014, 4(4):17-22.

[6] W Xie. Simulation of power electronics and AC drives [M]. Beijing: China Machine Press, 2009.

[7] S H Xie, S C Qu. Simulink Study on Control System of Brushless DC Motor based on Matlab[J].The Journal of New Industrialization. 2015, 5(3):28-34.

[8] Y P He, X H Nian. Permanent magnet synchronous motor vector control simulation of MATLAB [J]. Communication technology and electric traction. 2007, 6(2):58-62.

[9] Li SH, Liu ZG. Adaptive Speed Control for Permanent-Magnet Synchronous Motor System With Variations of load Inertia [J]. IEEE Transactions on Industrial Electronics, 2009,56(8):3050-3059.

[10] Chikh H K, et al. PMSM Vector Control Performance Improvement by Using Pulse with Modulation and Anti-Windup PI Controller. Proceedings of International Conference on Multimedia Computing and Systems, Chengdu, China, August 1-3, 2011: 1-7. 